Marianthi Manda, Nikolaos Moschakis, Avraam Konstantinidis, Demetrios Christophilos, Lambrini Papadopoulou, Petros Koidis and Elias Aifantis*

\title{
Probing the mechanical properties of dental porcelain through nanoindentation
}

\begin{abstract}
The purpose of this short communication is to report on some micro/nanoscale aspects of the mechanical behavior of dental porcelain. Specimens were characterized by micro-Raman spectroscopy and scanning electron microscopy (SEM) coupled with energy dispersive spectroscopy (EDS). Massive nanoindentation experiments on the surface of the specimens were performed, and typical load-displacement or load-depth (P-h) curves were obtained, which in turn were used to determine the Young modulus (E) and nanoindentation hardness $(n-H)$, based on the Oliver-Pharr method [1]. Statistical analyses were carried out to determine the Spearman's rank correlation coefficient (Spearman's $\rho$ ), along with non-parametric linear regression analysis by employing Kolmogorov-Smirnov and Two-Step Cluster tests. Densification due to grain boundary diffusion and open-pore elimination was revealed by SEM. EDS analysis indicated a leucite-dispersed silicate glass matrix, as well as its contamination by traces of other minerals. Raman spectroscopy supported the EDS assignments. The P-h curves suggested that inelastic deformation and material flow increases at larger depths. Spearman's $\rho$ value showed strong dependence of $\mathrm{E}$ and $\mathrm{n}-\mathrm{H}$ on $\mathrm{h}$, indicating the occurrence of a size effect. The logarithmic data of $\mathrm{E}$ and $\mathrm{n}-\mathrm{H}$ as functions of $\mathrm{h}$ were fitted by using linear regression analysis. The data did not obey a normal distribution (as the Kolmogorov-Smirnov test showed) due to the chemical heterogeneity involved. The Two-Step Cluster analysis indicated clustering in four groups associated with the chemical heterogeneity of the surface. Similar works using nanoindentation to determine the mechanical properties of dental materials can be found, for example, in [2, 3]. Corresponding methods for extracting the values of $E$ and $\mathrm{n}-\mathrm{H}$ from $\mathrm{P}-\mathrm{h}$ experimental curves can be found, for example, in [4-6].
\end{abstract}

Keywords: dental porcelain; micro-Raman spectroscopy; nanoindentation; size effect.

*Corresponding author: Elias Aifantis, School of Engineering, Aristotle University, Thessaloniki 54124, Greece,

e-mail: mom@mom.gen.auth.gr; Michigan Technological University,
Houghton, MI 49931, USA; and King Abdulaziz University, Jeddah 21589, Saudi Arabia

Marianthi Manda: School of Dentistry, Aristotle University, Thessaloniki 54124, Greece

Nikolaos Moschakis: School of Engineering, Aristotle University, Thessaloniki 54124, Greece

Avraam Konstantinidis: School of Engineering, Aristotle University, Thessaloniki 54124, Greece

Demetrios Christophilos: School of Engineering, Aristotle

University, Thessaloniki 54124, Greece

Lambrini Papadopoulou: School of Geology, Aristotle University, Thessaloniki 54124, Greece

Petros Koidis: School of Dentistry, Aristotle University, Thessaloniki 54124, Greece

\section{Specimen fabrication and characterization}

Dental porcelain powder in the $\mathrm{SiO}_{2}-\mathrm{Al}_{2} \mathrm{O}_{3}-\mathrm{K}_{2} \mathrm{O}-\mathrm{Na}_{2} \mathrm{O}$ oxide system - used for margin restoration of fixed partial dentures (IPS Inline Margin Ceramic System; Ivoclar Vivadent AG, Schaan, Liechtenstein) - was mixed with the modeling liquid (IPS Inline Margin, Build-Up Liquid; Ivoclar Vivadent AG, Shaan, Liechtenstein) into a water-based thick slurry. The liquid-to-powder mixing weight ratio was 0.335 (according to the manufacturer). The mixtures were molded in cylindrical polyvinyl-siloxane dies of $6 \times 1.5 \mathrm{~mm}$ (diameter $\times$ height) and condensed using vibration and drying techniques. The resultant disk specimens were gently removed from the molds, and sintering to the recommended end temperature $\left(930^{\circ} \mathrm{C}\right)$ for the firing cycle of the dental porcelain followed. The firing cycle occurred in vacuum with a rate of $60^{\circ} \mathrm{C} / \mathrm{min}$ (Progamat P700; Ivoclar Vivadent AG, Shaan, Liechtenstein).

The so-obtained specimens were characterized by using (a) SEM coupled with EDS (JSM 840A; JEOL SA, Tokyo, Japan) and (b) micro-Raman spectroscopy, using a triple-grating spectrometer system ("XY"; Dilor, Lille, France), with an incorporated Olympus microscope and a liquid nitrogen-cooled CCD detector to record the Raman spectra in a backscattering geometry. A 514.5-nm line of an $\mathrm{Ar}^{+}$laser was used for excitation at a power of $\sim 20 \mathrm{~mW}$ 

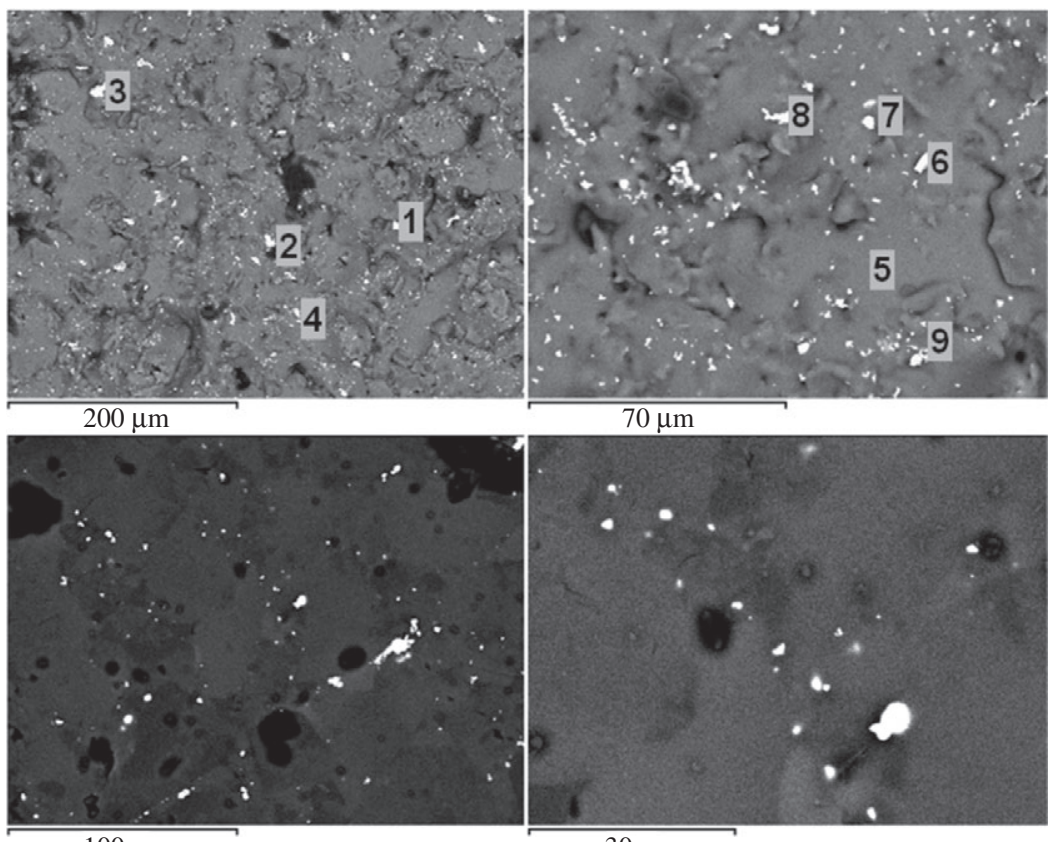

$100 \mu \mathrm{m}$

$30 \mu \mathrm{m}$

Figure 1 SEM surface (top) and cross-sectional (bottom) images of the surface of dental porcelain specimens.

The numbers correspond to representative areas on the surface of dental porcelain, which were measured by using EDS analysis (Table 1).

measured just before the microscope objective. The most representative EDS and Raman spectra are discussed below.

\subsection{SEM analysis}

Surface SEM images of the dental porcelain specimen are presented in Figure 1. A typical microstructure of sintered dental porcelain is observed, which is consistent with those reported previously [7-9]. A high densification and absence of open porosity are apparent. The morphology consists of a dark gray smooth and fine background, where trace bright gray agglomerates are dispersed within. The EDS analysis of the dark substrate reveals the significant presence of silica ( $\mathrm{Si}$ ) and oxygen (O), indicating the considerable contribution of silicate glass network, whereas the probing of $\mathrm{K}$ and $\mathrm{Al}$ provides

\begin{tabular}{|c|c|c|c|c|c|c|c|c|c|}
\hline & & & & & & & & & Areas \\
\hline & 1 & 2 & 3 & 4 & 5 & 6 & 7 & 8 & 9 \\
\hline 0 & 26.77 & 28.68 & 29.53 & 21.77 & 52.48 & 24.07 & 28.08 & 22.80 & 32.16 \\
\hline $\mathrm{Na}$ & - & 1.81 & 0.64 & - & 4.32 & - & 1.24 & - & 2.46 \\
\hline $\mathrm{Al}$ & - & 3.13 & 1.57 & 1.19 & 8.87 & 0.74 & 2.99 & 2.29 & 14.99 \\
\hline $\mathrm{Si}$ & 1.54 & 8.47 & 11.46 & 2.11 & 28.63 & 3.63 & 1.47 & - & 3.83 \\
\hline $\mathrm{K}$ & 0.90 & - & 1.91 & 0.79 & 5.69 & 1.38 & - & - & - \\
\hline $\mathrm{Ca}$ & - & - & - & - & - & - & - & - & - \\
\hline $\mathrm{Zr}$ & 70.79 & - & - & - & - & - & 66.10 & - & - \\
\hline $\mathrm{Sn}$ & - & 57.91 & - & - & - & - & - & 74.91 & - \\
\hline $\mathrm{Zn}$ & - & - & & 74.14 & - & - & - & - & - \\
\hline$Y$ & - & - & 51.21 & - & - & 70.07 & - & - & 41.91 \\
\hline $\mathrm{Ce}$ & - & - & 3.67 & - & - & - & - & - & 4.66 \\
\hline $\mathrm{Ti}$ & - & - & - & - & - & 0.11 & 0.13 & - & - \\
\hline
\end{tabular}

Table 1 Weight percent of elements detected from EDS analysis on representative areas on the surface of the dental porcelain. 


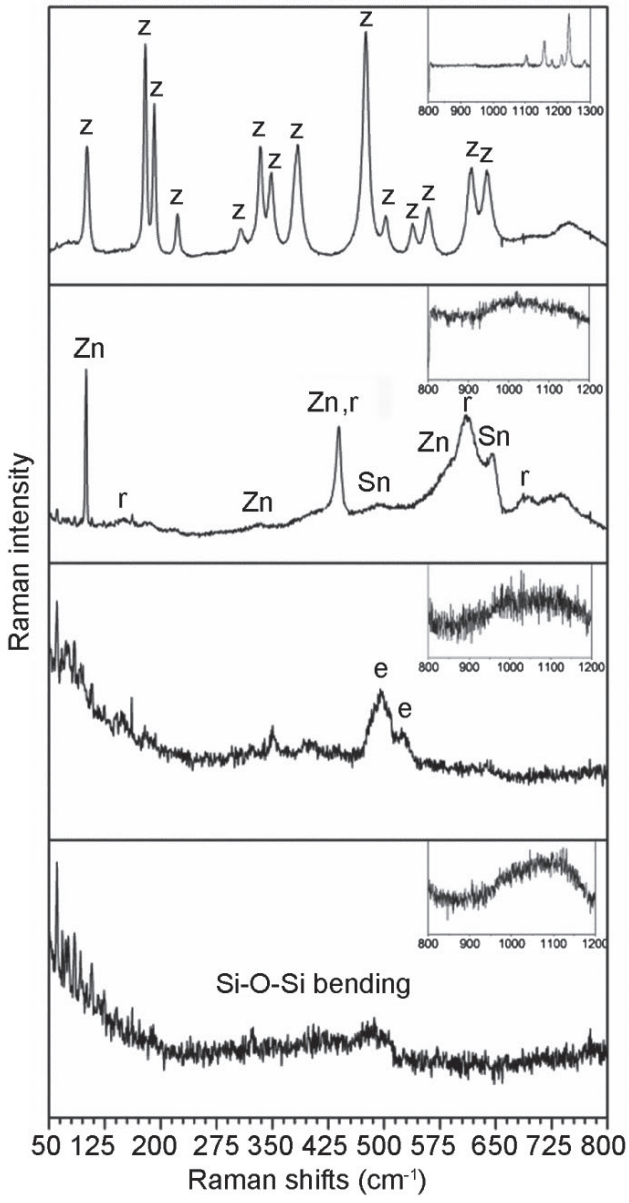

Figure 2 Raman spectra from the surface of dental porcelain specimens.

The following abbreviations were used for the phases detected: $z$ $\left(\mathrm{ZrO}_{2}\right) ; \mathrm{zn}(\mathrm{ZnO}) ; \mathrm{sn}\left(\mathrm{SnO}_{2}\right) ; \mathrm{r}\left(\mathrm{TiO}_{2}\right)$; e (leucite).

evidence of surface crystallization of leucite phases [8]. The bright gray grains are identified with Sn-, Zn-, Y-, Ce-, and Zr-rich phases as the EDS data revealed. Traces of Ti have also been detected (Table 1).

\subsection{Raman analysis}

Figure 2 illustrates the most representative Raman spectra obtained from the surface of dental porcelain specimens, selected by using light microscopy. The majority of the measurements involved two predominant spectra that are related to (a) the amorphous silicate matrix and (b) the leucite phase. The amorphous matrix is distinguished by two broad bands between 400 and $650 \mathrm{~cm}^{-1}$, which are attributed to the bending vibration of isolated $\mathrm{SiO}_{4}$ tetrahedra, and one broad band centered at $1100 \mathrm{~cm}^{-1}$, which is assigned to $\mathrm{Si}-\mathrm{O}$ stretching vibrations [10]. Leucite phases are identified by two peaks located at 495 and $526 \mathrm{~cm}^{-1}$, which stem from the T-O-T bending modes $(\mathrm{T}=\mathrm{Al}$ or $\mathrm{Si})[11-$ 13]. The Raman spectra of crystalline phases corresponding to zirconium oxide $\left(\mathrm{ZrO}_{2}\right)$, zinc oxide/Wurtzite $(\mathrm{ZnO})$, rutile $\left(\mathrm{TiO}_{2}\right)$, and cassiterite $\left(\mathrm{SnO}_{2}\right)$ are obtained through surface measurements. The spectrum of $\mathrm{ZrO}_{2}$ is dominated by several well-defined sharp intense peaks typical of its monoclinic phase. Wurtzite $\mathrm{ZnO}$ is distinguished by the highly intense peaks at 100 and $441 \mathrm{~cm}^{-1}$ (related to the E2 Raman-active modes) and at $589 \mathrm{~cm}^{-1}$ (related to the E1 Raman-active mode). Indications of rutile are derived from the peaks positioned at $642 \mathrm{~cm}^{-1}$ (Eg phonon mode) and $441 \mathrm{~cm}^{-1}$ (A1g phonon mode), the latter of which is shared by $\mathrm{ZnO}$. The Raman modes observed at $491 \mathrm{~cm}^{-1}(\mathrm{Eg})$ and $642 \mathrm{~cm}^{-1}$ (A1g) are related to $\mathrm{SnO}_{2}$. These conclusions were deduced in consultation with [14-17].

\section{Mechanical testing - nanoindentation}

After material characterization, the specimens were (a) embedded in epoxy resin (Epofix resin; Struers Inc., Cleveland, USA), (b) placed in a vacuum chamber for
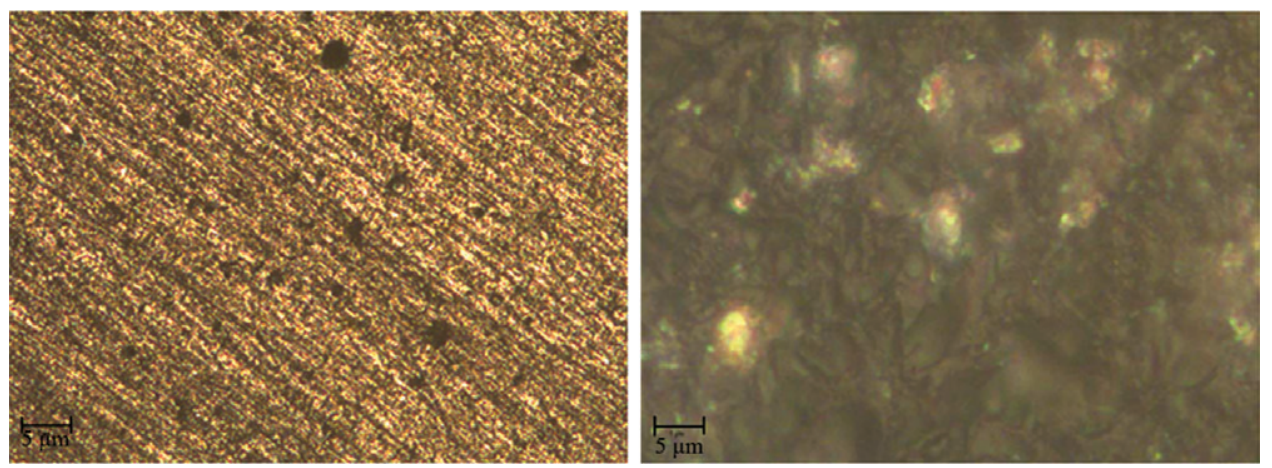

Figure 3 Light microscope photos of the indented dental porcelain surface specimen. Image magnification: $\times 20$ (left) and $\times 100$ (right). 

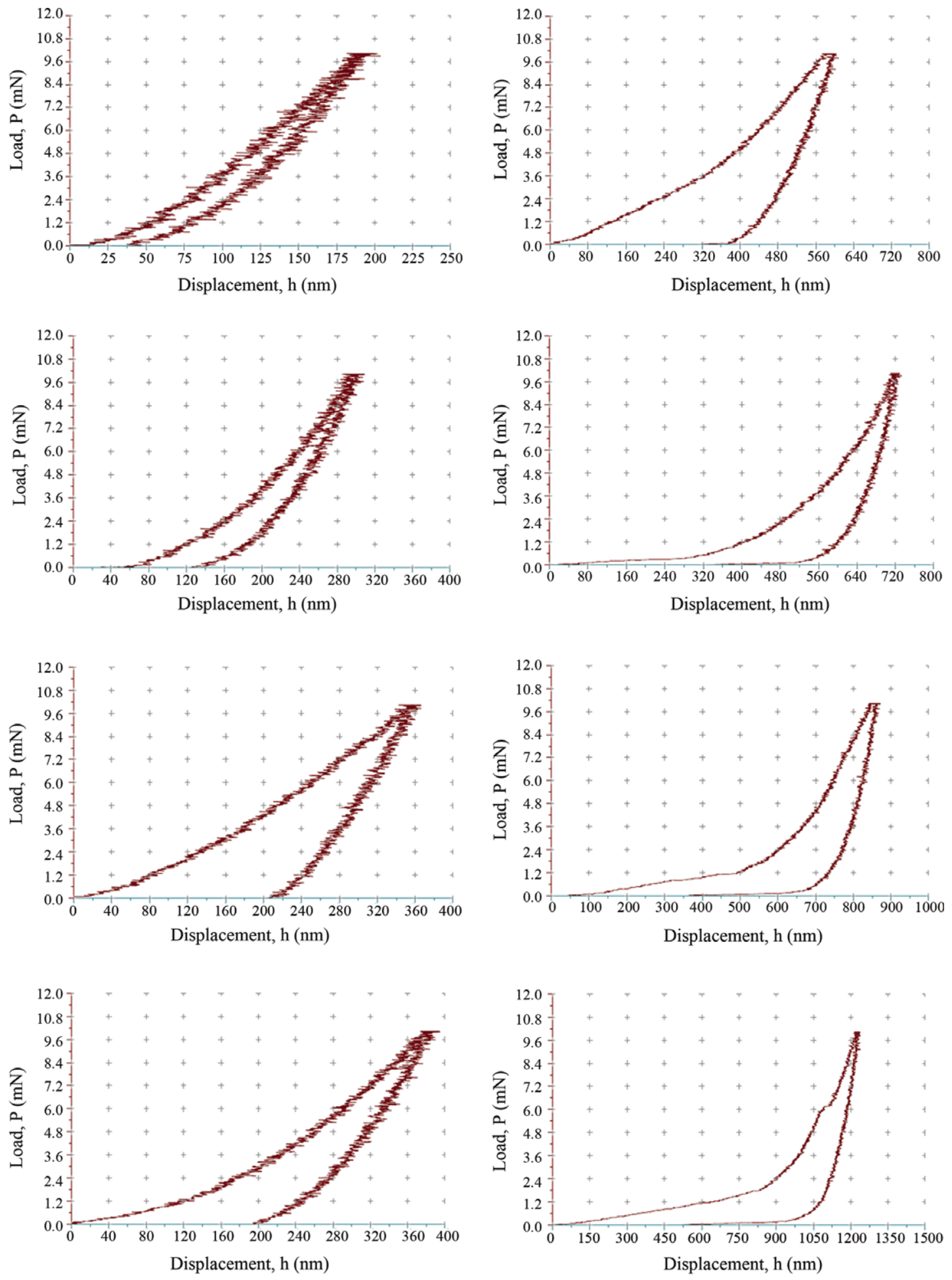

Figure 4 Representative load-displacement (P-h) curves of dental porcelain specimens.

5 min, (c) light-cured for $20 \mathrm{~min}$, (d) mounted to microscopic slides, (e) cut down to $0.25 \mu \mathrm{m}$ along the sagittal plane using a high-speed microtome (Accutom II ${ }^{\oplus}$; Struers Inc., Cleveland, USA), (f) grinded using 1200-4000 grit $\mathrm{SiC}$ disks in a grinding-polishing device (DAP-V ${ }^{\oplus}$; Struers Inc., Cleveland, USA), and (g) polished with diamond paste. This way, the specimens were flat, smooth, stable, and ready to be subjected to nanoindentation tests. A NanoHardness Tester-NHT (CSM Instruments, SA, Peseux, Switzerland) was used, equipped with a light microscope, after calibration on fused silica. An area representative of the heterogeneity exhibited by the surface (as perceived 
by light microscopy with a magnification $\times 100$ ) was selected, captured by the attached light-sensitive camera, and indented. Indents were performed with a triangular pyramidal Berkovich tip under maximum load of $10 \mathrm{mN}$ (load control mode). A constant loading-unloading rate $(5 \mathrm{mN} / \mathrm{s}$ ) was used, and the holding period between the loading and the unloading phase was $20 \mathrm{~s}$. The imprint of the $10-\mathrm{mN}$ indent could not be distinguished by light microscopy. Consequently, an accumulative tetragonal indentation array of $20 \times 20$ (400) indents, separated by $5 \mu \mathrm{m}$ to avoid interaction but accounting for the heterogeneity of the surface, was conducted. The indentation process was registered as a real-time display by plotting the applied load as a function of the penetration depth during both the loading and the unloading phases (load/ displacement curves). $\mathrm{E}$ and $\mathrm{n}-\mathrm{H}$ were calculated from the indentation stiffness (S) measured from the slope in the upper portion of the initial stage of the unloading curve, which is assumed to be elastic. As already mentioned, the calculations were based on the Oliver-Pharr method [1]. The results collected were subsequently subjected to statistical analysis (SPSS version 19.0//IBM Statistics 19) as follows: (a) calculation of the Spearman's rank correlation coefficient (Spearman's $\rho$ ), based on non-parametric data, to estimate the statistical correlation between $\mathrm{E}$ or $\mathrm{n}-\mathrm{H}$ and $\mathrm{h}$; (b) performance of non-parametric linear regression analysis for the logarithmic data; (c) employment of the Kolmogorov-Smirnov test $(n>50)$ to assess the appropriateness of the normal distribution to fit the data; (d) use of the Two-Step Cluster analysis to reveal possible grouping (clustering), which could be identified with the participating crystal and glass phases on the surface of the specimen.

\subsection{Load-displacement/depth (P-h) curves}

A total of 400 P-h curves were obtained, of which $~ 27 \%$ were excluded from consideration due to substantial deviation from typical responses, malfunctioning of the nanoindenter, or other calibration factors. Figure 3 displays the indented surface area, whereas Figure 4 illustrates the most representative P-h curves for dental porcelain specimens. The P-h curves follow an elastic-plastic-like behavior, which appears to also be influenced by the penetration depth. The curves show an almost completely elastic response for shallow (200-250 nm) penetration depths, whereas plastic deformation becomes more pronounced toward larger total displacements. For large displacements or penetration depths approaching $1 \mu \mathrm{m}$, the P-h plot exhibited an initial segment of large displacement under slight load increases, followed by typical P-h behavior, whereas the same is observed at the final part of the unloading curve. In the latter curves, single or double bursts (also referred as pop-in events) appear in the loading curve, whereas no distinct discontinuities were recorded for penetration depths not exceeding 400-500 nm.

\subsection{Statistical analysis}

Scatter plots of $\mathrm{E}$ and $\mathrm{n}-\mathrm{H}$ as functions of $\mathrm{h}$ are given in Figure 5. In Tables 2 and 3, the values of correlation coefficients quantifying the above dependence, are given. A correlation of 0 indicates no dependence, whereas \pm 1.0 indicates perfect positive and negative or inverse dependence. The significance level of the correlations obtained from two-tailed tests is presented as well [Significance (2-tailed)].

Scatter plots and corresponding fits obtained through linear regression for the logarithmic data of $\mathrm{E}$ and $\mathrm{n}-\mathrm{H}$ in relation to $\mathrm{h}$ will be reported in a follow-up article. It will be seen therein how well linear regression approximates the real data. In particular, it may be concluded from the corresponding Spearman's $\rho$ values that there is a strong inverse relationship between $\mathrm{E}$ and penetration depth, whereas the $n-H$ exhibits an almost perfect inverse
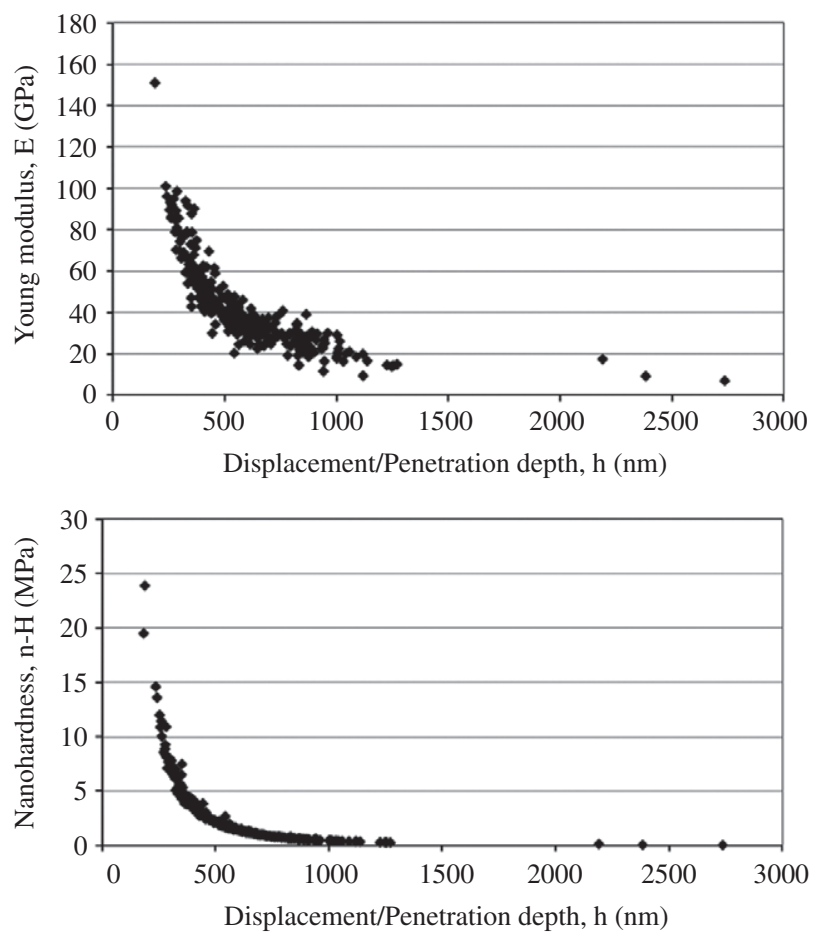

Figure 5 Scatter plots of $\mathrm{E}$ (upper) and $\mathrm{n}-\mathrm{H}$ (lower) vs. penetration depth. 
$\mathrm{E}(\mathrm{GPa})$

Spearman's $\rho$ Displacement, Correlation coefficient $\quad-0.936$

$\mathrm{h}(\mathrm{nm}) \quad$ Significance (two-tailed) $<0.001$

290

Table 2 Spearman's $\rho$ value for the correlation between $\mathrm{E}$ and $\mathrm{h}$.

$\mathrm{n}-\mathrm{H}(\mathrm{MPa})$

\begin{tabular}{lllr}
\hline Spearman's $\rho$ & Displacement, & Correlation coefficient & -0.997 \\
& $\mathrm{~h}(\mathrm{~nm})$ & Significance (two-tailed) & $<0.001$ \\
& $\mathrm{n}$ & 290 \\
\hline
\end{tabular}

Table 3 Spearman's $\rho$ value for the correlation between $\mathrm{n}-\mathrm{H}$ and $\mathrm{h}$. correlation with the penetration depth. Related histograms of normal and logarithmic data for $\mathrm{E}$ and $\mathrm{n}-\mathrm{H}$ vs. $\mathrm{h}$, (derived from the Kolmogorov-Smirnov test) indicate that they do not fit to a normal distribution, and the frequency plots provide evidence for clustering. This is further documented by a Two-Step Cluster analysis revealing that there are four groups that fit the data. All these will be discussed in detail in a future follow-up article, where similar results on bioactive materials will also be reported.

Acknowledgments: The authors acknowledge discussions with Katerina E. Aifantis (K.E.A.), and the third author (A.K.), in particular, gratefully acknowledges the support of the European Research Council under the ERC Starting Grant MINATRAN (No. 211166), under the direction of K.E.A.

\section{References}

[1] Oliver WC, Pharr GM. MRS Bull. 2010, 35, 897-907.

[2] Willems G, Celis JP, Lambrechts P, Braem M, Vanherle G. J. Biomed. Mater. Res. 1993, 27, 747-755.

[3] He LH, Swain MV. Dent. Mater. 2007, 23, 814-821.

[4] Poon B, Rittel D, Ravichandran G. Int. J. Sol. Struct. 2008, 45, 6018-6033.

[5] Poon B, Rittel D, Ravichandran G. Int. J. Sol. Struct. 2008, 45, 6399-6415.

[6] Mukhopahyay NK, Paufler P. Int. Mater. Rev. 2006, 51, 209-245.

[7] Cattell MJ, Chadwick TC, Knowles JC, Clarke RL. Dent. Mater. 2005, 21, 811-822.

[8] Pisitanusorn A, Yimnirun R, Ananta S. Chiang Mai J. Sci. 2011, 38, 590-600.

[9] Fredericci C, Yoshimura HN, Molisani AL, Bellinati CE, Alcantara RQE, Cesar PF. Mater. Sci. Forum 2008, 591-593, 692-696.
[10] Shim S-H, Catalli K. Earth Planet Sci. Lett. 2009, 283, 174-180.

[11] Ovsyuka N, Goryainov S. JETP Lett. 2006, 83, 138-142.

[12] Castriota M, Cosco V, Barone T, De Santo G, Carafa P, Cazzanelli E. J. Raman Spectrosc. 2008, 39, 295-301.

[13] McKeown DA, Buechele AC, Viragh C, Pegg IL. J. Nucl. Mater. 2010, 399, 13-25.

[14] Siu GG, Stokes MJ, Liu Y. Phys. Rev. B. 1999, 59, 3173-3179.

[15] McGuire K, Pan ZW, Wang ZL, Milkie D, Menéndez I, Rao AM. J. Nanosci. Nanotechnol. 2002, 5, 499-502.

[16] Barros AD, Albertin KF, Miyoshi J, Doi I, Diniz JA. Microelectron. Eng. 2010, 87, 443-446.

[17] Rammutla KE, Chadwick AV, Harding J, Sayle DC, Erasmus RM. J. Phys.: Conf. Series 2010, 249, 1-5. 